\title{
EFFECT OF 2-AMINO-3-ETHOXYCARBONYL-6-BENZYL-4,5,6,7- TETRAHYDROTHIENO [2,3-C] PYRIDINE (TINORIDINE) ON FATTY ACID COMPOSITION OF LIVER LYSOSOMES FROM A VITAMIN E DEFICIENT DIET TO RATS
}

\author{
Tadashi FUJITA and Masahide YASUDA \\ Department of Hygienic Chemistry, Osaka College of Pharmacy, Matsubara, Osaka, Japan
}

Accepted July 24, 1973

The effect of Tinoridine (2-amino-3-ethoxycarbonyl-6-benzyl-4, 5, 6, 7-tetrahydrothieno [2, 3-C] pyridine) in stabilizing lysosomal membrane of a rat liver has been demonstrated (1). Dingle, et al. (2) reported that lysosomal membrane of kidney from vitamin E-deficient rats appeared to be very labile but stabilization in liver was no different from that in the control.

The fatty acid analysis $(3,4)$ has cleary demonstrated that there are marked changes in fatty acid composition in the mitochondria and microsomes from the liver of vitamin E-deficient rats, therefore, it seemed of interest to investigate the alterations of liver lysosomal lipid in vitamin E-deficient rats.

Male Wistar rats, weighing $150-200 \mathrm{~g}$, were fed a vitamin E-deficient diet and the control animals were fed a standard laboratory dict supplemented with $100 \mathrm{mg}$ of $\alpha$-tocopheryl acetate per $\mathrm{kg}$ of food. After three weeks the animals were decapitated and vitamin E deficiency state was determined according to the method described by Ikehata et al. (5). The drug ( $\alpha$-tocopherol, Tinoridine hydrochloride) was administered to each rat in a saline suspension containing $1 \%$ of Tween 80 .

Lysosomal fraction was prepared by the method of Weissmann (6). Protein content in the lysosome was estimated as described by Lowry et al. (7). The lysosomal suspension used contained $3 \mathrm{mg} / \mathrm{ml}$ of protein suspended in $0.25 \mathrm{M}$ sucrose.

The fatty acid composition of lysosomes was determined by gas-liquid chromatography $(8,9)$, with hydrogen ionization detector. The glass columns ( $4 \mathrm{~mm} \times 1.86 \mathrm{~m})$ were packed with $15 \%$ cthyleneglycoladipate polyester on Chromosorb $W$. The column was operated at $200^{\circ}$ with a nitrogen flow rate of $60 \mathrm{~mL} / \mathrm{min}$.

The methyl esters of fatty acids were obtained by methylation of the lipids with $5 \%$ $\mathrm{HCl}$-methanol for $2 \mathrm{hr}$ and were identified by comparison with the retention time of authentic standards. Statistical cvaluation by Student's $t$-test was made to compare appropriate controls to treated animals.

Changes in fatty acids occurring in lysosomal lipids of treated rats, as compared to controls, are shown in Table I. The major fatty acis in normal animals were saturated $\left(C_{16: 0,}, C_{18: 0}\right)$ and unsaturated $\left(C_{1: 11}, C_{18: 2}, C_{29: 4}, C_{33: 6}\right)$ fatty acids. A clear percentage increase in palmitoleic acid and olcic acid was observed $(p<0.01)$; on the other hand, lino- 
TABLE 1. Effect of $\alpha$-tocopherol and tinoridine on fatty acids of liver lysosomes of Vitamin $\mathbf{E}$ deficient rats

\begin{tabular}{|c|c|c|c|c|c|}
\hline Chain length & Control & $-\mathrm{VE}^{\mathrm{a})}$ & $\left.+V E^{b}\right)$ & \multicolumn{2}{|c|}{ Tinoridine $e^{e>}$} \\
\hline $\mathrm{C}_{14: 0}$ & $\therefore$ & + & + & + & \\
\hline $\mathrm{C}_{16: 0}$ & $21.17 \pm 0.69$ & 26.03 上0.88 & $22.03 \pm 0.16$ & $21.73 \pm 0.27$ & $\mathrm{P}<0.02$ \\
\hline$C_{16: 1}$ & + & $9.07 \pm 1.09$ & $1.43 \pm 0.88$ & $2.80 \pm 0.25$ & $\mathrm{P}<0.01$ \\
\hline $\mathrm{C}_{18: 0}$ & $21.13 \pm 0.80$ & $16.33 \pm 0.35$ & $23.40 \pm 0.24$ & $20.93 \pm 0.54$ & $\mathrm{P}<0.01$ \\
\hline $\mathrm{C}_{18: 1}$ & $9.40 \pm 1.10$ & $20.10 \pm 0.44$ & $15.53 \pm 0.23$ & $19.13 \pm 0.74$ & \\
\hline $\mathrm{C}_{18: 3}$ & $19.63 \pm 0.76$ & $8.53 \pm 0.15$ & $11.17 \pm 0.22$ & $10.03 \pm 0.11$ & $\mathrm{P}<0.05$ \\
\hline $\mathrm{C}_{18: 3}$ & + & + & + & + & \\
\hline $\mathrm{C}_{20: 0}$ & $+t$ & & & & \\
\hline $\mathrm{C}_{20: 2}$ & $\div$ & $\div$ & + & + & \\
\hline $\mathrm{C}_{20: 4}$ & $22.67 \pm 1.19$ & $17.13 \pm 1.15$ & $22.60 \pm 0.25$ & $20.27 \pm 0.01$ & $\mathrm{P}<0.05$ \\
\hline $\mathrm{C}_{22: 8}$ & $6.80+0.44$ & $2.30 \pm 0.15$ & $5.53 \pm 0.58$ & $4.67 \pm 0.43$ & $P<0.01$ \\
\hline
\end{tabular}

Plus sign indicates a trace amount. a ; Vitamin E-deficient rat, b; i.p. administration of $\alpha$-tocopherol $(100 \mathrm{mg} / \mathrm{kg} / \mathrm{day}, \times 5), \mathrm{c}$; i.p. administration of tinoridine (100 $\mathrm{mg} / \mathrm{kg} / \mathrm{day}, \times 5$.

All values are the mean \pm S.E. of percentage of fatty acids in three experiments. P-values was determined by comparing Vitamin E-deficient groups to tinoridine treated animals.

leic, arachictonic and docosthextenoic acids were decreased in the lysosomal fraction from the liver of vitamin E-deficient animals. The larger decrease was found in linolcic and docosahexaenoic acids (ca. 50\%, respectively) and the smaller decrease in arachidonic acid (ca. $25 \%$ ).

After i.p. administration of $\alpha$-tocopherol $(100 \mathrm{mg} / \mathrm{kg})$ to vitamin E-deficient rats for 5 days, the contents of palmitoleic and oleic acids in liver lysosomes decreased, while linoleic, arachidonic, and docosahexaenoic acids were elevated by treatment with $\alpha$-tocopherol.

In the application of Tinoridine $(100 \mathrm{mg} / \mathrm{kg}$, i.p.), the contents of palmitoleic and oleic acids, which inereased in the liver lysosomes from vitamin F-deficient rats, decreased but the consistently lower percentage of finoleic, arachidonic, and docosahexaenoic acids in deficient animals was significantly elevated in the Tinoridine-treated group.

The observed decrease in polyunsaturated falty acids was interpreted on the basis of lipid peroxidation by vitamin E-deficiency. However, in vitamin E-deficiency states there is an increased content of monoenoic acids in lysosomes. Therefore, one may speculate that specific changes in fatty acid metabolism may be involved in the liver of vitamin E-deficient rats.

Vitamin $E$ has functions other than that of an antioxidant; it may play a role in the stabilization of biological membranes which contain a high level of polyunsaturated fatty acids.

It can be concluded from the results of the present work that Tinoridine has the same protective effect as vitamin $E$ on changes with fatty acid composition in the liver lysosomal lipids from vitamin E-deficient animals. Mechanism of the action of Tinoridine on lipids of subcellular organelles in now being investigated, 
Acknowledgment: The authors wish to thank Yoshitomi Pharmaceutical Industries, Lid. for the generous gift of Tinoridine.

\title{
REFERENCES
}

1) Nakanishi, M., Imamura, H. AND Goto, K.: Yahugaha Zasshi 90, 557 (1970) (in Japanese);

2) Dinglf, T.J., Sharman, M.I. and Moore, T.: Biochem. J. 98, 476 (1966): 3) Fujita, T., Yasuda, M., Kutamlera, Y. and SHimamura, S.: Yakugahu Zasshi 92, 670 (1972) (in Japanese); 4) Vos, J., Molenaar, I., Searle-Yan Lfhlwhin, M. and Hommes, F.A.: Ani. N.Y. Acad. Sci. 203, 72 (1972); 5) IKLitata, M., Koyavagi, K. ANiD WaKalZGMi, M.: Vitamins 37, 37 (1968); 6) Wesssmann, G.: Biochem. Pharmacol. 14, 525 (1955); 7) Lowry, O.H., Rosebrovgh, N.H., Farr, A.L. and Ravdall, R.J.: \%. biol. Chem. 193, 265 (1951); 8) Stoffel, W., Chu, F. AND Ahrens, E.H.: Anal. Chem. 31, 307 (1959); 9) Funta, T.: Yakugaku Zasshi 92, 250 (1972) (in Japanese)

\section{EFFECT OF L-5HTP ON TREMORINE- OR OXOTREMORINE- INDUCED TREMOR IN MICE AND RATS}

\author{
Kenji OHMORI and Tetsuo KOJIMA \\ Pharmaceutical Research Laboratories, Fuji Plant, Kyowa Hakko Kogyo Co., Lid., \\ Shizuoka, Japan
}

Accepted July 25, 1973

According to the most predominant hypothesis, Parkinsonism, the main symptoms of which arc tremor, muscle rigidity and akinesia, seems to result from disturbances in the basal ganglia, especially disturbance of the amine balance between the cholinergic and dopaminergic system in the corpus strialum $(1,2)$. L-Dopa (L-dihydroxyphenylalanine) has recently been used, as well as anticholincrgic agents, antihistamines and phenothiazines. in the treatment of Parkinsonism. Nlhough it is remarkably effective against muscle rigidity and akinesia, L-dopa shows only slight inhibition against tremor both in animal experiments and clinical cases (3). Some authors ascribe Parkinsonism to a decrease in intracerebral 5-HT (5-hydroxytryptamine) level (4) and there are reports about the application of 5-HTP (5-hydroxytryptophan), a metabolic precursor of 5-HT, to the treatment of Parkinsonism $(5,6)$.

Tremorine-induced tremor, first described by G.M. Everetl (7), is mos! frequently used to elucidate the mechanism of tremor and in the primary screening of anti-Parkinsonism. R. Rodoriguez observed that DL-5HTP slightly inhibited tremorine-induced tremor in mice (8). Goldstein et al. have indicated that upon tremor in monkeys with mesencephalic lesions, inhibitory effect was observed with high doses of DL-5HTP and that atropine was intensified by DL-5HTP, the dose of the latter being such as to cause no tremor-inhibition (9. 10).

To determine further the role of 5-HT in extrapyramidal dysfunction, the effect of L-5HTP, on tremorine- and oxotremorine-induced tremor was investigated herein.

Male adult dds mice weighing 19 to $21 \mathrm{~g}$ and male adult Wister rats weighing 180 